\title{
An analysis of $\mathrm{CO}_{2}$ elimination curves during artificial ventilation
}

\author{
Genro Ochi ${ }^{1}$, Yasushi Takasaki ${ }^{2}$, Toshihiro Yorozuya ${ }^{2}$, Yukio Nakashita ${ }^{2}$, Ko Kuzume ${ }^{2}$, Takumi Nagaro², \\ and Tatsuru AraI ${ }^{2}$ \\ ${ }^{1}$ Emergency Clinic and ${ }^{2}$ Department of Anesthesiology and Resuscitology, Ehime University School of Medicine, Shitsukawa, Shigenobu- \\ Town, Onsen-Gun, Ehime, 791-02 Japan
}

\begin{abstract}
We have developed some indices to evaluate the phase III slope in $\mathrm{CO}_{2}$ elimination curves. The indices were applied to 12 mechanically ventilated patients in ICU to determine their stability under various ventilator settings. $\mathrm{F}_{\mathrm{CO}^{-}}$ $\mathrm{sl}[30-90]$ and $\dot{\mathrm{V}}_{\mathrm{CO}}$-sl[30-90] expressed the mean incline of

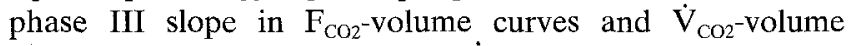
curves, respectively. $\mathrm{F}_{\mathrm{CO} 2}-\mathrm{SR}$ and $\dot{\mathrm{V}}_{\mathrm{CO} 2}-\mathrm{SR}$ expressed the ratio of the slopes in the first and second halves of the phase III portion in both curves. The indices were also applied to 108 elective surgery patients to determine their usefulness in predicting ventilatory efficiency during general anesthesia. In the first study, $\mathrm{F}_{\mathrm{CO} 2}-\mathrm{sl}[30-90]$ and $\dot{\mathrm{V}}_{\mathrm{CO} 2}[30-90]$ correlated with $\mathrm{ET}_{\mathrm{CO} 2}, \mathrm{~V}_{\mathrm{D}} / \mathrm{V}_{\mathrm{T}}$ and the volume of $\mathrm{CO}_{2}$ expired, but $\mathrm{F}_{\mathrm{CO} 2}-\mathrm{SR}$ and $\dot{\mathrm{V}}_{\mathrm{CO} 2}-\mathrm{SR}$ were independent of these parameters. $\dot{\mathrm{V}}_{\mathrm{CO} 2}-\mathrm{SR}$ did not show any significant changes under various ventilator settings except for application of PEEP. In the second study, those with impaired preoperative respiratory function had significantly larger values for $\dot{\mathrm{V}}_{\mathrm{CO}^{2}}-\mathrm{SR}$. $\dot{\mathrm{V}}_{\mathrm{CO}}$-SR was as sensitive as parameters such as $\mathrm{V}_{\mathrm{D}} / \mathrm{V}_{\mathrm{T}}$, arterial to end-tidal $\mathrm{CO}_{2}$ tension difference $\left(\mathrm{a}-\mathrm{ET} \cdot \mathrm{D}_{\mathrm{CO} 2}\right)$, and volume pressure index (VPI) in predicting poor respiratory functions. We concluded that $\dot{\mathrm{V}}_{\mathrm{CO} 2}-\mathrm{SR}$ is a useful index for evaluating the phase III slope in $\mathrm{CO}_{2}$ elimination curves.
\end{abstract}

Key words: $\mathrm{CO}_{2}$ elimination curves, Capnography, Single breath test, Monitoring, Artificial ventilation

\section{Introduction}

Capnometry has become a valuable measurement tool for continuous respiratory monitoring and has gained widespread use in ICUs, in anesthetic management and in monitoring during cardiopulmonary resuscitation. With controlled mechanical ventilation, a normal

Address correspondence to: $\mathrm{G}$. Ochi

Received for publication on March 4, 1993; accepted on October 7, 1993 capnogram has a rectangular appearance and is divided into four phases: I, inspiratory baseline; II, expiratory upstroke; III, expiratory "plateau"; and IV, inspiratory downstroke [1]. However, it is known that alveolar $\mathrm{CO}_{2}$ concentration $\left(\mathrm{F}_{\mathrm{A}} \mathrm{CO}_{2}\right)$ shows cyclic variation and that a slight upward slope instead of a plateau is usually observed in phase III [2-4]. It is also known that the slope becomes steeper in case of respiratory diseases in which asynchronous emptying of lung regions with differing V/Q ratios takes place [5-7]. Therefore, being able to evaluate the steepness of phase III slope will be valuable for estimating the efficiency of $\mathrm{CO}_{2}$ elimination and for the diagnosis of respiratory diseases. However, neither indices nor standards have been developed to evaluate the phase III slope quantitatively.

In this study we developed some new indices for evaluating the phase III slopes, and applied them to mechanically ventilated patients in ICU and in the operating room. This study's aim was to determine whether our indices were stable under various ventilator settings and were predictive of respiratory function of patients under artificial ventilation.

\section{Patients and methods}

The protocol was approved by Ehime University Ethical Committee and informed consent was obtained from each patient or his/her family when the patient was unconscious.

Study 1: analysis of $\mathrm{CO} 2$ curves under various ventilator settings

The study group consisted of 12 mechanically ventilated patients who were admitted to Ehime University Hospital Intensive Care Unit. These patients consisted of 8 males and 4 females, with an average age of 58.3 years (from 23 to 86 ). 
The patients were sedated with $5-10 \mathrm{mg}$ of midazolam, and 4-6 $\mathrm{mg}$ of pancuronium bromide were administered intravenously prior to the study. All patients were ventilated with seven ventilator modes each for 5-10 min per mode until $\mathrm{ET}_{\mathrm{CO} 2}$ became stable (Servo $900 \mathrm{C}$ or Bear 5 ventilators). The settings were as follows. Control (C): intermittent positive pressure ventilation (IPPV) with a tidal volume of $8-10 \mathrm{ml} / \mathrm{kg}$ and a respiratory rate of 12 breaths/min. A control tidal volume was determined which would maintain $\mathrm{ET}_{\mathrm{CO} 2}$ between $4.8 \%$ and $5.2 \% . \mathrm{P} 1$ and $\mathrm{P} 2: 5(\mathrm{P} 1)$ or $10(\mathrm{P} 2)$ $\mathrm{cmH}_{2} \mathrm{O}$ of Positive End-Expiratory Pressure (PEEP) was added to the control setting. R1 and R2: only respiratory rate (breaths/min) was changed to 8 (R1) and 16 (R2) from the control setting. V1 and V2: tidal volume was decreased (V1) and increased (V2) by $15 \%$ from the control values.

We measured the expiratory flow rate using a hotwire flowmeter (Minato ME, Osaka, Japan). The $\mathrm{CO}_{2}$ concentration $\left(\mathrm{F}_{\mathrm{CO} 2}\right)$ of expired gas was measured using an infrared spectrophotometer with a side-stream sensor (MG360, Minato ME), and the time delay of $F_{\mathrm{CO} 2}$ measurements were corrected. The measured data were digitized with an analog-digital converter (PC-módule

\section{FECO2}
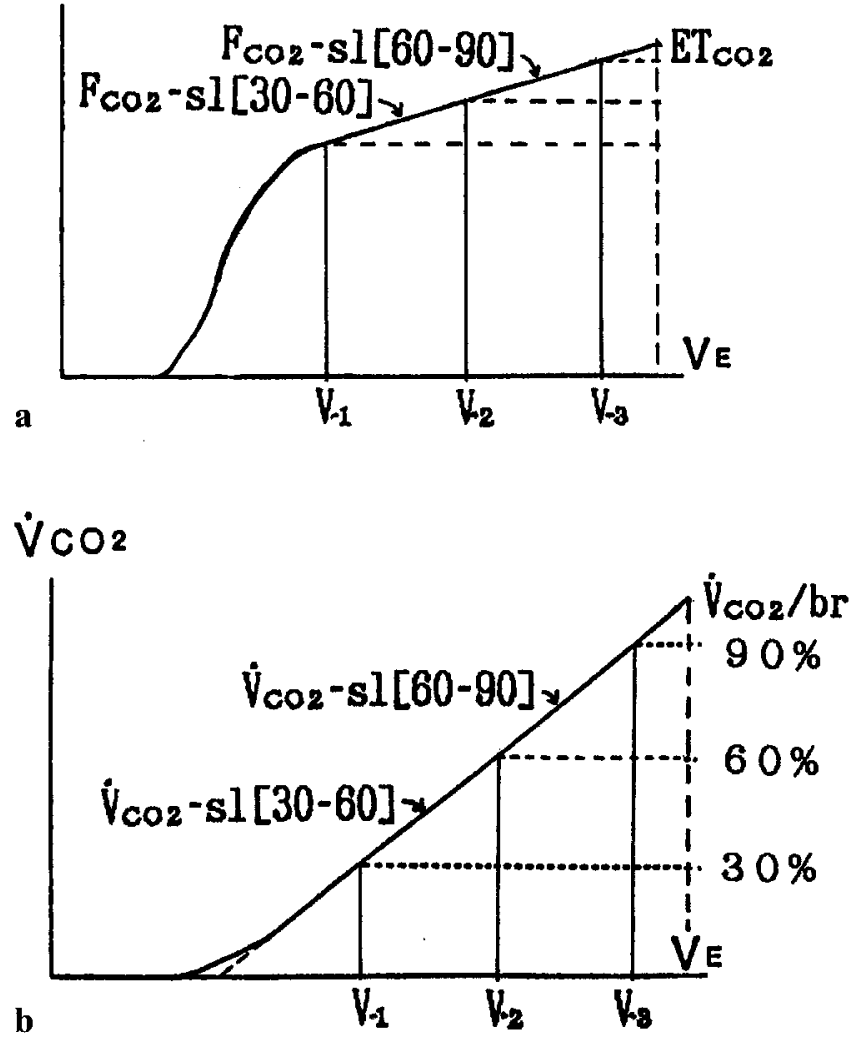

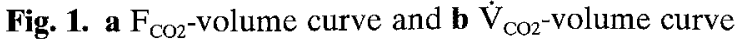

Table 1. Calculated parameters

\begin{tabular}{|c|c|}
\hline $\begin{array}{l}\mathrm{F}_{\overline{\mathrm{ECO}} 2} \\
\mathrm{~V}_{\mathrm{D}} / \mathrm{V}_{\mathrm{T}} \\
\ddot{\mathrm{V}}_{\mathrm{CO} 2} / \mathrm{min} \\
\mathrm{F}_{\mathrm{CO} 2}-\mathrm{SR} \\
\dot{\mathrm{V}} \mathrm{CO}_{2}-\mathrm{SR} \\
\mathrm{V}_{\mathrm{D}} / \mathrm{V}_{\mathrm{T}}^{\prime} \\
\mathrm{a}-\mathrm{ET} \cdot \mathrm{D}_{\mathrm{CO} 2} \\
\mathrm{AaDO} \\
\mathrm{VPI}(\mathrm{L} \mathrm{mml}\end{array}$ & 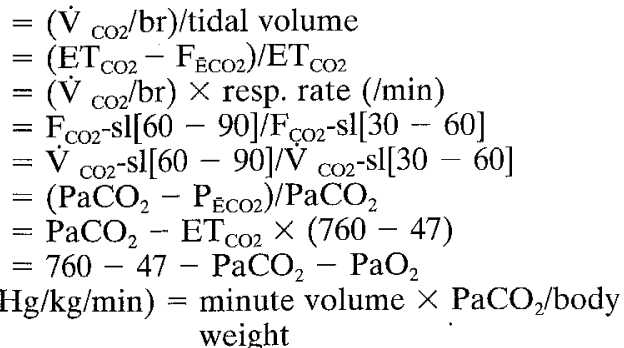 \\
\hline
\end{tabular}

AD12-16TA, Contec) and were recorded by a computor (PC-9800DA, NEC, Tokyo, Japan) at 10-ms intervals. We calculated the expiratory volume by integrating the flow rate and the rate of $\mathrm{CO}_{2}$ elimination $\left(\dot{\mathrm{V}}_{\mathrm{CO} 2}\right)$ by integrating the product of $\mathrm{F}_{\mathrm{CO} 2}$ and flow rate.

With the above parameters $\mathrm{F}_{\mathrm{CO} 2}$ volume curves and $\dot{\mathrm{V}}_{\mathrm{CO} 2}$-volume curves were plotted against expiratory volume (Fig. 1). The total elimination volume of $\mathrm{CO}_{2}$ during a breath was called $\dot{\mathrm{V}}_{\mathrm{CO} 2}$ /br and the expiratory volumes at which $30 \%, 60 \%$, and $90 \%$ of $\dot{\mathrm{V}}_{\mathrm{CO} 2} /$ br was exhaled were named $\mathrm{V}-1, \mathrm{~V}-2$, and $\mathrm{V}-3$, respectively. $\mathrm{F}_{\mathrm{CO}^{2}}$-slope(sl) [30-60], $\mathrm{F}_{\mathrm{CO}^{2}}$-slope(sl) [60-90], and $\mathrm{F}_{\mathrm{CO}^{-}}$ slope(sl) [30-90] were defined as the average slopes of $\mathrm{F}_{\mathrm{CO} 2}$ from $\mathrm{V}-1$ to $\mathrm{V}-2, \mathrm{~V}-2$ to $\mathrm{V}-3$, and $\mathrm{V}-1$ to $\mathrm{V}-3$ in the $\mathrm{F}_{\mathrm{CO}^{2}}$-volume curve, respectively. $\mathrm{F}_{\mathrm{CO} 2}$-slope ratio (SR) was defined as the quotient of $\mathrm{F}_{\mathrm{CO}_{2}-\mathrm{sl}}[60-90]$ and $\mathrm{F}_{\mathrm{CO}^{-}}$ sl[30-60] (Table 1). $\dot{\mathrm{V}}_{\mathrm{CO} 2}$-sl[30-60], $\dot{\mathrm{V}}_{\mathrm{CO} 2}$-sl[60-90], $\dot{\mathrm{V}}_{\mathrm{CO}^{2}}$-sl[30-90], and $\dot{\mathrm{V}}_{\mathrm{CO}^{2}}-\mathrm{SR}$ in the $\dot{\mathrm{V}}_{\mathrm{CO}^{2}}$-volume curve were also defined in the same way. Other calculated parameters are as listed in Table 1.

The statistical analysis was performed as follows. Paired $t$-test was applied to compare the parameters under seven ventilator settings. The linear correlations between the parameters were analyzed with correlation analysis. Statistical significance was accepted as $P<0.05$.

Study 2: analysis of correlations between preoperative respiratory function and values from $\mathrm{CO}_{2}$ elimination curves

The study group consisted of 108 patients who underwent elective surgery under general anesthesia. There were 48 men and 60 women, with an average age of 56.1 years (from 15 to 80). Preoperatively the patients were tested for percent Vital Capacity (\%VC), $\mathrm{FEV}_{1.0 \%}$ and $\dot{\mathrm{V}}_{50} / \dot{\mathrm{V}}_{25}$ (Riko, RIMCOS-II).

Anesthesia was induced with $4-10 \mathrm{mg}$ of midazolam and $0.2-0.5 \mathrm{mg}$ of fentanyl administered intravenously. The patients were immobilized with $4-6 \mathrm{mg}$ of vecuronium bromide and were intubated with cuffed endotracheal tubes. IPPV was instituted with an $\mathrm{F}_{\mathrm{i}} \mathrm{O}_{2}$ of 
1.0 , a tidal volume of $8-10 \mathrm{ml} / \mathrm{kg}$ and a respiratory rate of $1.2 \mathrm{breaths} / \mathrm{min}$. When a stable $\mathrm{ET}_{\mathrm{CO} 2}$ value of 4.4 to

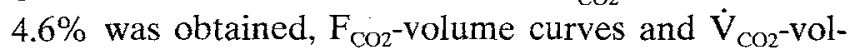
ume curves were drawn with the same methods used in Study 1 to calculated $\mathrm{F}_{\mathrm{CO}_{2}}$-SR and $\dot{\mathrm{V}}_{\mathrm{CO}}-\mathrm{SR}$. Arterial blood gas was analyzed to calculate $\mathrm{V}_{\mathrm{D}} / \mathrm{V}_{\mathrm{T}}$ (expressed as $\mathrm{V}_{\mathrm{D}} / \mathrm{V}_{\mathrm{T}}{ }^{\prime}$ in Study 2), arterial to end-tidal $\mathrm{CO}_{2}$ tension difference $\left(\mathrm{a}-\mathrm{ET} \cdot \mathrm{D}_{\mathrm{CO} 2}\right)$, Volume Pressure Index (VPI) [8] and alveolar to arterial $\mathrm{O}_{2}$ difference $\left(\mathrm{AaDO}_{2}\right)$. Formulas to calculate the above parameters are as shown in Table 1 and all the measurements were completed before the operation was started.

Patients with poor respiratory reserve were selected according to three preoperative parameters, and an additional five parameters during IPPV were compared between those selected and those who did not meet the criteria. Criteria for poor respiratory reserve included
$\% \mathrm{VC}$ of less than $80 \%, \mathrm{FEV}_{1.0 \%}$ of less than $70 \%$, and $\dot{\mathrm{V}}_{50} / \dot{\mathrm{V}}_{25}$ exceeding 4.0; parameters during IPPV included $\mathrm{F}_{\mathrm{CO} 2}-\mathrm{SR}, \dot{\mathrm{V}}_{\mathrm{CO} 2} \mathrm{SR}, \mathrm{V}_{\mathrm{D}} / \mathrm{V}_{\mathrm{T}}{ }^{\prime}, \mathrm{a}-\mathrm{ET} \cdot \mathrm{D}_{\mathrm{CO} 2}$, VPI, and $\mathrm{AaDO}_{2}$. Analysis of variance (ANOVA) was applied to examine the statistical significance.

\section{Results}

\section{Study 1}

Changes in respiratory parameters under various ventilator modes were as shown in Fig. 2. Changes in $\mathrm{ET}_{\mathrm{CO} 2}$ were observed in the ventilator modes of $\mathrm{R} 1, \mathrm{R} 2$, and $\mathrm{V} 1 . \mathrm{V}_{\mathrm{D}} / \mathrm{V}_{\mathrm{T}}$ increased in mode $\mathrm{P} 2 . \dot{\mathrm{V}}_{\mathrm{CO} 2} /$ min increased in modes R2 and V2, and decreased in modes R1 and V1.

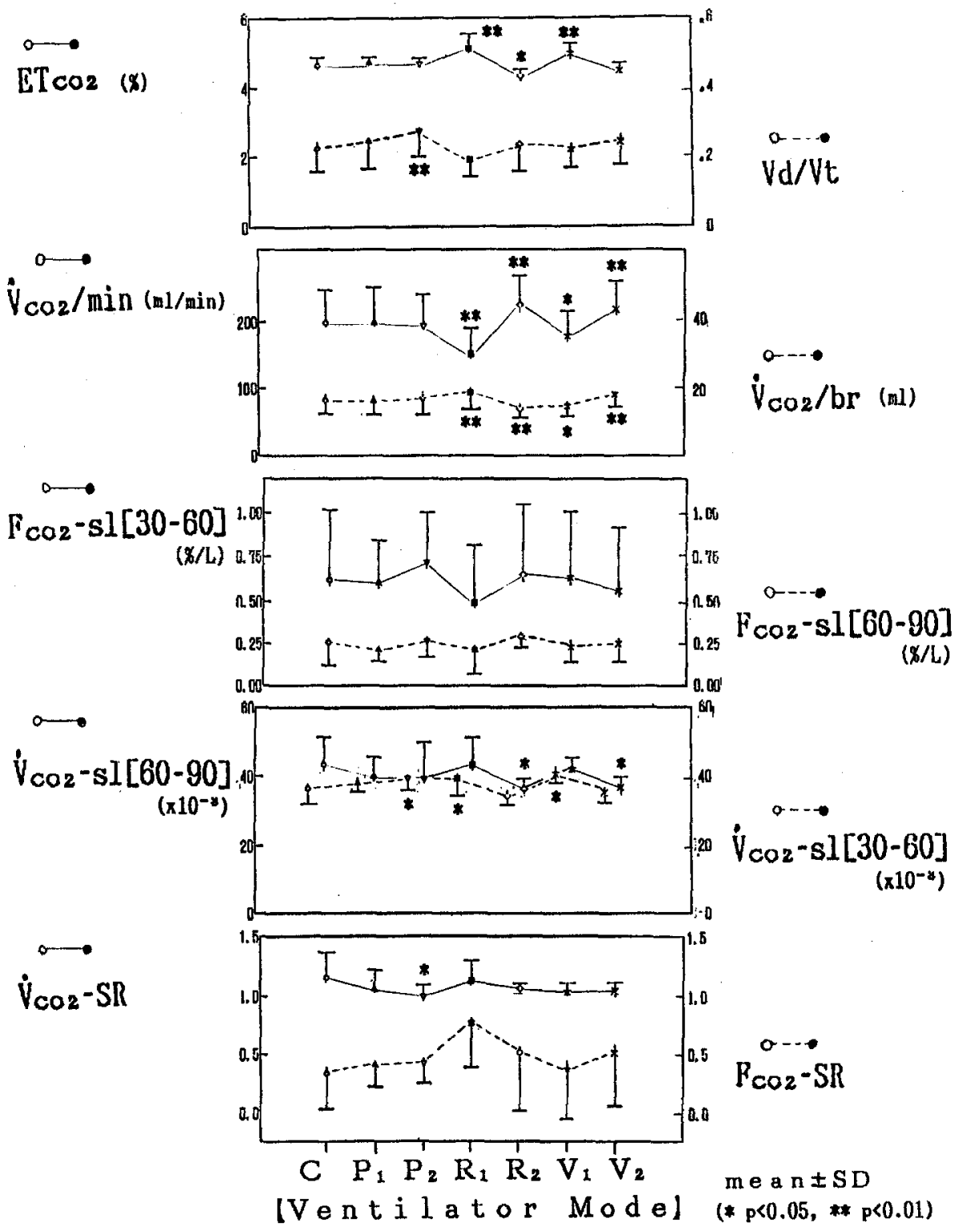

Fig. 2. Respiratory parameters under various ventilator modes 

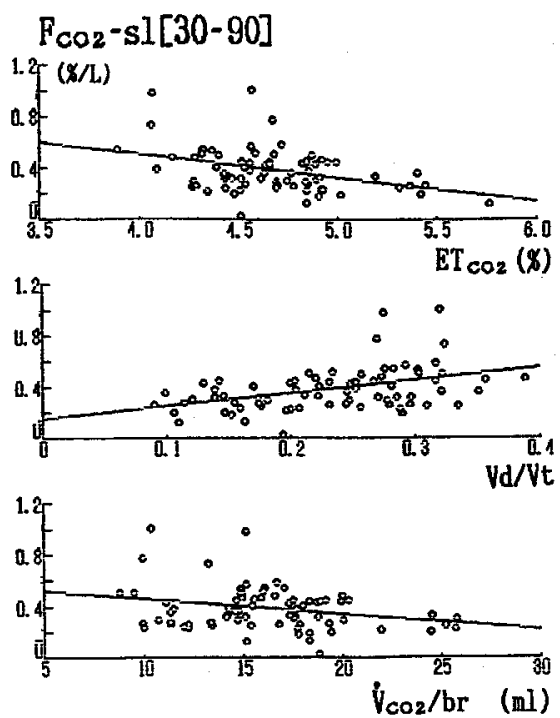

\section{$\dot{V}_{\mathrm{CO} 2}-\mathrm{s} 1[30-90]$}
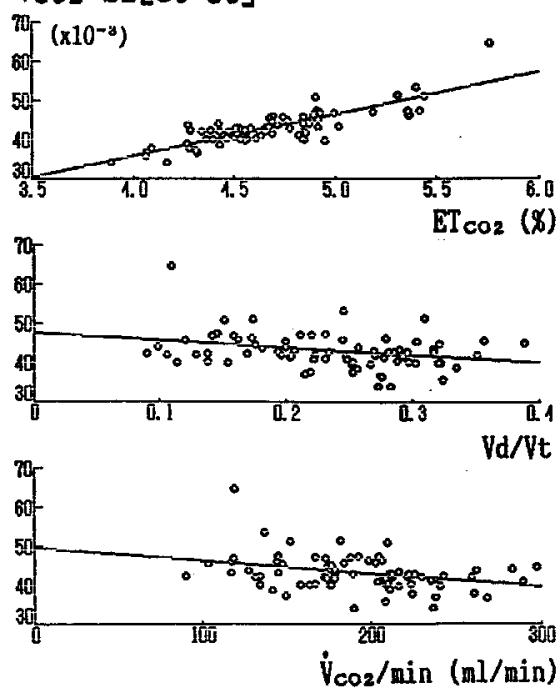
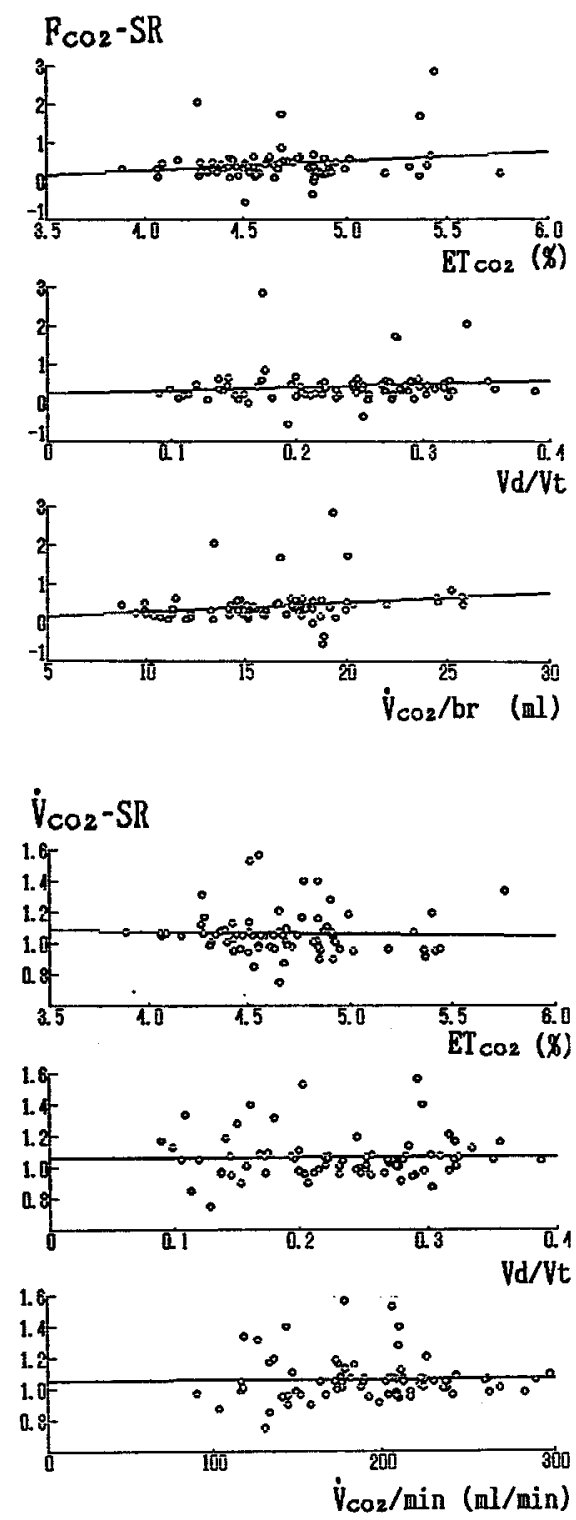

Fig. 3. Correlations between the parameters

Fig. 4. Correlations between the parameters
$\dot{\mathrm{V}}_{\mathrm{CO} 2} / \mathrm{br}$ increased in modes $\mathrm{R} 1$ and $\mathrm{V} 2$, and decreased in modes R2 and V1. $\mathrm{F}_{\mathrm{CO}^{2}}$-sl[30-60], $\mathrm{F}_{\mathrm{CO}_{2}}-\mathrm{sl}[60-90], \mathrm{F}_{\mathrm{CO}^{-}}$ sl[30-90], and $\mathrm{F}_{\mathrm{CO} 2}-\mathrm{SR}$ remained unchanged and the standard deviations (SDs) of the variables were very large. $\dot{\mathrm{V}}_{\mathrm{CO}^{2}}$-sl[30-60] increased in modes P2, R1, and $\mathrm{V} 1 . \dot{\mathrm{V}}_{\mathrm{CO} 2}-\mathrm{sl}[60-90]$ decreased in modes $\mathrm{R} 2$ and V2. $\dot{\mathrm{V}}_{\mathrm{CO} 2}$-SR was unchanged except in mode $\mathrm{P} 2$ and the SDs of $\dot{\mathrm{V}}_{\mathrm{CO}}-\mathrm{SR}$ were smaller than those of $\mathrm{F}_{\mathrm{CO} 2}-\mathrm{SR}$.

Linear correlations between the parameters. Figures 3 and 4 show that $\mathrm{F}_{\mathrm{CO}_{2}}$-sl[30-90] correlated with $\mathrm{ET}_{\mathrm{CO} 2}$ $(r=-0.38)$, with $\mathrm{V}_{\mathrm{D}} / \mathrm{V}_{\mathrm{T}}(r=0.42)$, and with $\dot{\mathrm{V}}_{\mathrm{CO} 2} / \mathrm{br}$ $(r=-0.28) . \dot{\mathrm{V}}_{\mathrm{CO} 2}$-sl[30-90] correlated with $\mathrm{ET}_{\mathrm{CO} 2}(r=$ $0.83)$, with $\mathrm{V}_{\mathrm{D}} / \mathrm{V}_{\mathrm{T}}(r=-0.29)$ and with $\dot{\mathrm{V}}_{\mathrm{CO} 2} / \mathrm{min}$ $(r=-0.34) . \mathrm{F}_{\mathrm{CO}^{2}}-\mathrm{SR}$ and $\dot{\mathrm{V}}_{\mathrm{CO} 2}$-SR did not correlate with these parameters and the slopes of the regression lines were very small.
Study 2

As shown in Table 2, patients with lower \% VC $(n=20)$ had higher $\dot{\mathrm{V}}_{\mathrm{CO} 2}$-SR and larger VPI. Those with lower $\operatorname{FEV}_{1.0 \%}(n=12)$ had higher $\dot{\mathrm{V}}_{\mathrm{CO} 2}-\mathrm{SR}$, higher $\mathrm{V}_{\mathrm{D}} / \mathrm{V}_{\mathrm{T}}^{\prime}$, and larger a-ET. $\mathrm{D}_{\mathrm{CO} 2}$. Those with higher $\dot{\mathrm{V}}_{50} / \dot{\mathrm{V}}_{25}$ $(n=16)$ did not show significant differences in any of the parameters during IPPV.

\section{Discussion}

Arterial blood gases (ABGs) are commonly employed as an indicator of respiratory function and adequacy of respirator settings in patients under respiratory support. However, they require invasive procedures and the data obtained are not provided continuously [9]. Conversely, 
Table 2. Analysis of correlations between preoperative respiratory function and values from $\mathrm{CO}_{2}$ elimination curves

\begin{tabular}{|c|c|c|c|c|c|c|c|}
\hline $\begin{array}{l}\% \text { VC } \\
\text { group }\end{array}$ & $\% \mathrm{VC}$ & $\mathrm{F}_{\mathrm{CO}_{2}}-\mathrm{SR}$ & $\dot{\mathrm{V}}_{\mathrm{CO}^{2}}-\mathrm{SR}$ & $\mathrm{V}_{\mathrm{D}} / \mathrm{V}_{\mathrm{T}}^{\prime}$ & $\mathrm{a}-\mathrm{ET} \cdot \mathrm{D}_{\mathrm{CO} 2}$ & VPI & $\mathrm{AaDO}_{2}$ \\
\hline $\begin{array}{l}<80 \% \\
(n=20)\end{array}$ & $\begin{array}{c}68.5 * * \\
(9.7)\end{array}$ & $\begin{array}{c}0.828 \\
(0.233)\end{array}$ & $\begin{array}{l}1.08 * \\
(0.05)\end{array}$ & $\begin{array}{l}47.5 \\
(7.7)\end{array}$ & $\begin{array}{c}6.93 \\
(3.90)\end{array}$ & $\begin{array}{l}4.46^{*} \\
(1.25)\end{array}$ & $\begin{array}{l}178 \\
(67)\end{array}$ \\
\hline $\begin{array}{l}>=80 \% \\
(n=88)\end{array}$ & $\begin{array}{r}105.5 \\
(14.6)\end{array}$ & $\begin{array}{c}0.800 \\
(0.293)\end{array}$ & $\begin{array}{c}1.05 \\
(0.05)\end{array}$ & $\begin{array}{l}46.2 \\
(6.9)\end{array}$ & $\begin{array}{c}6.47 \\
(3.65)\end{array}$ & $\begin{array}{c}3.91 \\
(0.86)\end{array}$ & $\begin{array}{l}202 \\
(88)\end{array}$ \\
\hline $\begin{array}{l}\mathrm{FEV}_{1.0 \%} \\
\text { group }\end{array}$ & $\mathrm{FEV}_{1.0 \%}$ & $\mathrm{~F}_{\mathrm{CO}_{2}}-\mathrm{SR}$ & $\dot{\mathrm{V}}_{\mathrm{CO} 2}-\mathrm{SR}$ & $\mathrm{V}_{\mathrm{D}} / \mathrm{V}_{\mathrm{T}}^{\prime}$ & $\mathrm{a}-\mathrm{ET} \cdot \mathrm{D}_{\mathrm{CO} 2}$ & VPI & $\mathrm{AaDO}$ \\
\hline $\begin{array}{l}<70 \% \\
(n=12)\end{array}$ & $\begin{array}{c}59.3^{* * *} \\
(6.9)\end{array}$ & $\begin{array}{c}0.833 \\
(0.193) \\
\end{array}$ & $\begin{array}{l}1.12 * * \\
(0.07)\end{array}$ & $\begin{array}{l}52.8 * \\
(9.3)\end{array}$ & $\begin{array}{c}10.32 * * \\
(5.28)\end{array}$ & $\begin{array}{l}4.53 \\
(1.37)\end{array}$ & $\begin{array}{l}202 \\
(80)\end{array}$ \\
\hline $\begin{array}{l}>=70 \% \\
(n=96)\end{array}$ & $\begin{array}{l}82.9 \\
(6.8)\end{array}$ & $\begin{array}{c}0.802 \\
(0.292)\end{array}$ & $\begin{array}{c}1.05 \\
(0.05)\end{array}$ & $\begin{array}{l}45.7 \\
(6.3)\end{array}$ & $\begin{array}{c}6.09 \\
(3.17)\end{array}$ & $\begin{array}{c}3.95 \\
(0.89)\end{array}$ & $\begin{array}{l}197 \\
(85)\end{array}$ \\
\hline $\begin{array}{l}\dot{\mathrm{V}}_{50} / \dot{\mathrm{V}}_{25} \\
\text { group }\end{array}$ & $\dot{\mathrm{V}}_{50} / \dot{\mathrm{V}}_{25}$ & $\mathrm{~F}_{\mathrm{CO}_{2}}-\mathrm{SR}$ & $\dot{\mathrm{V}}_{\mathrm{CO} 2}-\mathrm{SR}$ & $\mathrm{V}_{\mathrm{D}} / \mathrm{V}_{\mathrm{T}}^{\prime}$ & $\mathrm{a}-\mathrm{ET} \cdot \mathrm{D}_{\mathrm{CO} 2}$ & VPI & $\mathrm{AaDO}_{2}$ \\
\hline $\begin{array}{l}<4.0 \\
(n=16)\end{array}$ & $\begin{array}{l}4.73 * * \\
(0.49)\end{array}$ & $\begin{array}{c}0.781 \\
(0.252)\end{array}$ & $\begin{array}{c}1.06 \\
(0.04)\end{array}$ & $\begin{array}{l}48.4 \\
(4.8)\end{array}$ & $\begin{array}{c}6.65 \\
(2.59)\end{array}$ & $\begin{array}{c}3.94 \\
(0.91)\end{array}$ & $\begin{array}{l}213 \\
(85)\end{array}$ \\
\hline $\begin{array}{l}>=4.0 \\
(n=92)\end{array}$ & $\begin{array}{c}2.56 \\
(0.78)\end{array}$ & $\begin{array}{c}0.809 \\
(0.288)\end{array}$ & $\begin{array}{c}1.06 \\
(0.06)\end{array}$ & $\begin{array}{l}46.1 \\
(7.3)\end{array}$ & $\begin{array}{c}6.54 \\
(3.85)\end{array}$ & $\begin{array}{c}4.07 \\
(1.01)\end{array}$ & $\begin{array}{l}187 \\
(83)\end{array}$ \\
\hline
\end{tabular}

Values are expressed as mean (SD).

$* P<0.05$; * $P<0.01$.

measurement of expired gases and calculation of respiratory mechanics are noninvasive methods of continuous monitoring of respiratory functions. When expiratory flow $\left(\dot{\mathrm{V}}_{\mathrm{E}}\right)$ and $\mathrm{F}_{\mathrm{CO} 2}$ are measured simultaneously, a plot of $\mathrm{F}_{\mathrm{CO} 2}$ against expiratory volume can be presented on a breath-by-breath basis. A number of noninvasive variables are obtained from the single breath test for $\mathrm{CO}_{2}\left(\mathrm{SBT}-\mathrm{CO}_{2}\right)$; i.e., $\mathrm{ET}_{\mathrm{CO} 2}, \mathrm{~V}_{\mathrm{D}}$ (Bohr), airway deadspace $\left(\mathrm{V}_{\mathrm{Daw}}\right)$, tidal volume $\left(\mathrm{V}_{\mathrm{T}}\right), \mathrm{V}_{\mathrm{D}} / \mathrm{V}_{\mathrm{T}}$, tidal elimination of $\mathrm{CO}_{2}\left(\dot{\mathrm{V}}_{\mathrm{CO} 2} / \mathrm{br}\right)$, slope of phase III, and so on.

Phase III in a $\mathrm{CO}_{2}$ elimination curve represents expiration of the alveolar gas. It usually forms a slight upward slope as alveolar $\mathrm{CO}_{2}$ continues to be supplied from the blood and $\mathrm{F}_{\mathrm{A}} \mathrm{CO}_{2}$ rises progressively toward the end of expiration. Several factors are known to affect the slope, and it becomes steeper whenever tidal volume is decreased, expiratory time is shortened, and/ or $\dot{\mathrm{V}}_{\mathrm{CO} 2}$ increases. It is also known that the steepness of the slope reflects asynchronous emptying of the lung, and that an increased slope is seen in patients with respiratory diseases such as bronchitis, emphysema, and asthma [5-7]. Thus the phase III slope can be used to detect abnormalities in the lung not detected by ABGs, and for this purpose some indices which are not affected by respiratory patterns and/or by $\dot{\mathrm{V}}_{\mathrm{CO} 2}$ should be applied. However, we do not have commonly accepted indices for the analysis of the slope except for one by Fletcher et al. [10] which is obtained by dividing an increase in $\mathrm{F}_{\mathrm{CO} 2}$ during a single phase III slope by mean
$\mathrm{F}_{\mathrm{CO} 2}$ during the phase. We did not use it because it can be influenced by $\mathrm{F}_{\overline{\mathrm{ECO}} 2}$ levels and by $\dot{\mathrm{V}}_{\mathrm{CO} 2}$.

In the first study, we developed some indices for the analysis of phase III slopes, and we determined their usefulness under various ventilator settings. First, we compared three types of $\mathrm{CO}_{2}$ elimination curves: $\mathrm{F}_{\mathrm{CO}^{-}}$

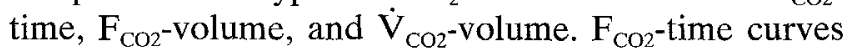
are most commonly monitored in ICUs and in anesthesia practices. However, there is a likelihood of being influenced by mechanical errors especially in the endexpiratory phase in which the expiratory flow rate $(\dot{V})$ is small. Although the other curves also are not free from electrical noises, when integrated values such as expiratory volume or $\dot{\mathrm{V}}_{\mathrm{CO} 2}$ are used, appropriate data can be obtained without using sophisticated techniques for filtering the noise.

Three standard volumes for calculating the slope in $\mathrm{CO}_{2}$ elimination curves were defined as the volumes at which $30 \%, 60 \%$, and $90 \%$ of $\dot{\mathrm{V}}_{\mathrm{CO} 2}$ br were eliminated. With ordinary ventilator settings, the total volume of $\mathrm{CO}_{2}$ exhaled during phase I and II does not reach $30 \%$ of $\dot{\mathrm{V}}_{\mathrm{CO} 2} / \mathrm{br}$. The end-expiratory portion in which the last $10 \%$ of $\mathrm{CO}_{2}$ is eliminated is omitted because the point between the expiratory plateau and the inspiratory downstrokes is sometimes obscure.

Using these standard volumes in the $\mathrm{CO}_{2}$ elimination curves, two types of indices for evaluating the steepness of phase III slope were originated. The first was to express the mean incline of the slope directly, i.e., $\mathrm{F}_{\mathrm{CO}^{-}}{ }^{-}$ $\mathrm{sl}[30-90]$ and $\dot{\mathrm{V}}_{\mathrm{CO} 2}-\mathrm{sl}[30-90]$. The second was to ex- 
press the ratio of the incline in the first and the second halves of the slope, i.e., $\mathrm{F}_{\mathrm{CO}_{2}}-\mathrm{SR}$ and $\dot{\mathrm{V}}_{\mathrm{CO} 2}$-SR. We expected that by using quotients of the two halves of the slope ratio, abnormal increase in $\mathrm{F}_{\mathrm{CO} 2}$ in the late expiration phase could be detected sensitively, and also influence of respiratory modes and $\dot{\mathrm{V}}_{\mathrm{CO} 2}$ would be diminished.

Changes in ventilator settings resulted in changes in some respiratory parameters. Changes in $\mathrm{ET}_{\mathrm{CO} 2}$ were induced by the changes in alveolar ventilation $\left(V_{A}\right)$. An increase in $V_{\mathrm{D}} / \mathrm{V}_{\mathrm{T}}$ associated with PEEP can be attributed to mismatching of $\mathrm{V} / \mathrm{Q}$ ratio induced by overdistension of alveoli [11]. Although significant changes were observed in $\dot{\mathrm{V}}_{\mathrm{CO} 2} / \mathrm{min}, \mathrm{CO}_{2}$ production seemed to be stable during the study and also the efficiency of ventilation was unchanged except when PEEP $10 \mathrm{cmH}_{2} \mathrm{O}$ was applied. Our data agreed with the study by Aoki et al. [12] which showed that the change in $\mathrm{CO}_{2}$ elimination was proportional to $V_{E}$ during artificial ventilation as the $\mathrm{CO}_{2}$ store of the body varied depending on $\mathrm{V}_{\mathrm{E}}$.

Indices obtained from $\mathrm{F}_{\mathrm{CO} 2}$-volume curves did not show significant changes when the ventilator settings were changed. However, these data do not mean that the indices were stable under various ventilator settings, but that deviations of the values among patients were too large to satisfy statistical significance. In indices obtained from $\dot{\mathrm{V}}_{\mathrm{CO} 2}$-volume curves, deviation between patients seemed to be small, and $\dot{\mathrm{V}}_{\mathrm{CO}_{2}}-\mathrm{SR}$ did not show significant changes under various ventilator settings except for an application of PEEP.

The correlation studies revealed that indices such as $\mathrm{F}_{\mathrm{CO} 2}$-sl[30-90] and $\dot{\mathrm{V}}_{\mathrm{CO} 2}$-sl[30-90] were under the influence of $\mathrm{ET}_{\mathrm{CO} 2}, \mathrm{~V}_{\mathrm{D}} / \mathrm{V}_{\mathrm{T}}$, and $\dot{\mathrm{V}}_{\mathrm{CO} 2}$-sl/br. On the contrary, $\mathrm{F}_{\mathrm{CO} 2}-\mathrm{SR}$ and $\dot{\mathrm{V}}_{\mathrm{CO}^{2}}$-SR seemed to be independent of these parameters. These data suggest that $\mathrm{F}_{\mathrm{CO}_{2}}$-SR and $\dot{\mathrm{V}}_{\mathrm{CO} 2}$-SR are more independent of the ventilator settings and $\dot{\mathrm{V}}_{\mathrm{CO} 2}$ than the other indices.

In the second study, we applied our indices to the patients under general anesthesia, and compared them with four parameters which were commonly used as a respiratory monitor during artificial ventilation. $\mathrm{V}_{\mathrm{D}} / \mathrm{V}_{\mathrm{T}}{ }^{\prime}$ was calculated by using $\mathrm{PaCO}_{2}$ instead of $\mathrm{F}_{\mathrm{A}} \mathrm{CO}_{2}$ expressing physiological dead space of the lung. An enlargement of a-ET $\cdot \mathrm{D}_{\mathrm{CO} 2}$ is attributed to V/Q mismatching induced by lung diseases, decrease in cardiac output, and pulmonary embolism [6]. VPI is an index which reflects the efficiency of $\mathrm{CO}_{2}$ elimination [8]. $\mathrm{AaDO}_{2}$ is an index of oxygenation and it reflects intra-pulmonary shunt and $V / Q$ mismatching. It should be noted that all four parameters need data from ABGs and they do not provide continuous real-time information. In the results, we found that $\dot{\mathrm{V}}_{\mathrm{CO} 2}-\mathrm{SR}$ is at least as sensitive as $\mathrm{V}_{\mathrm{D}} / \mathrm{V}_{\mathrm{T}}$, a-ET. $\mathrm{D}_{\mathrm{CO} 2}$ and VPI, and is more sensitive than $\mathrm{AaDO}_{2}$. This indicates that $\dot{\mathrm{V}}_{\mathrm{CO} 2}-\mathrm{SR}$ is a useful index for diagnosing lung diseases and for continuous monitoring of the efficiency of $\mathrm{CO}_{2}$ exchange in the lung.

Lastly, a single breath test for $\mathrm{CO}_{2}$ and a single breath $\mathrm{N}_{2}$ washout test should be compared. The latter was developed by Comroe and Fowler [13] and has been applied clinically to detect uneven alveolar ventilation for more than 40 years. As this method uses nitrogen gas as a tracer, obtained data is unlikely to be affected by expiratory time or by $\dot{\mathrm{V}}_{\mathrm{CO} 2}$. However it requires an additional process of a single deep breath of $100 \%$ oxygen and an apparatus to measure $\mathrm{N}_{2}$ concentration. A single breath test for $\mathrm{CO}_{2}$ is not as sophisticated a technique and the information from it is obtained on a breath-by-breath basis. Although $\mathrm{CO}_{2}$ is not an ideal tracer for examining maldistribution in the lung, the indices we developed can be of good help in diagnosing and monitoring respiratory functions in patients under artificial ventilation.

We concluded that $\dot{\mathrm{V}}_{\mathrm{CO}_{2}}$-SR is a useful index for calculating the phase III slope in $\mathrm{CO}_{2}$ elimination curves and that it is predictive of respiratory function of patients under artificial ventilation. Further study is warranted to determine the diagnostic standard of this index.

\section{References}

1. Good ML (1992) Capnography: a comprehensive review. ASA Refresher Course Lectures 431

2. DuBois $A B$, Britt $A G$, Fenn WO (1952) Alveolar $\mathrm{CO}_{2}$ during the respiratory cycle. J Appl Physiol 4:535-548

3. Suwa K, Bendixen HH (1972) Pulmonary gas exchange in a tidally ventilated single alveolus model. J Apply Physiol 32:834841

4. Osborn JB (1974) Modern patient care in ICU, CCU and CPU. Clin Res Phys 7:57-80

5. Fletcher R, Johnson B, Cummings G, et al. (1981) The concept of deadspace with special reference to the single breath test for carbon dioxide. Br J Anaesth 53:77-88

6. Shapiro BA, Cane RD (1989) Blood gas monitoring: yesterday, today, and tomorrow. Crit Care Med 17:573-581

7. Okada $K$, Nagai $H$, Endo $H$, et al. (1984) - Expired $\mathrm{CO}_{2}$ measurement and its clinical interpretation (in Japanese with English abstract). ICU to CCU (Jpn J Intens Care Med) 8:723731

8. Yasumoto R, Maruyama S (1987) A simple index for evaluating the $\mathrm{CO}_{2}$-elimination of the lung (in Japanese with English abstract). Masui (Jpn J Anesthesiol) 36:676-679

9. Tobin MJ (1988) Respiratory monitoring in the intensive care unit. Am Rev Respir Dis 138:1625-1642

10. Fletcher R, Malmkvist L, Niklason L, et al. On-line measurement of gas exchange during cardiac surgery.

11. Shapiro BA (1991) Pulmonary effects of positive end-expiratory pressure. In: Shapiro BA (ed) Clinical application of respiratory care. Mosby Year-Book, St. Louis, pp 335-343

12. Aoki A, Hayami H, Ishida H (1989) Steady state during mechanical ventilation: a report on the changes in body $\mathrm{CO}_{2}$ store (in Japanese with English abstract). ICU to CCU (Jpn J Intens Care Med) 13:811-817

13. Comroe JH Jr, Fowler WS (1951) Lung function studies. VI. Detection of uneven alveolar ventilation during a single breath of oxygen. Am J Med 10:408-413 